\title{
Downregulation of microRNA-30a-5p contributes to the replication of duck enteritis virus by regulating Beclin-1- mediated autophagy
}

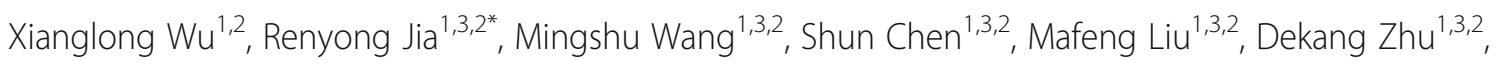

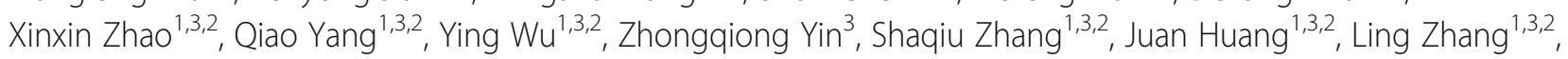
Yunya Liu ${ }^{1,3,2}$, Yanling Yu ${ }^{1,3,2}$, Leichang Pan ${ }^{1,3,2}$, Bin Tian ${ }^{1,3,2}$, Mujeeb Ur Rehman ${ }^{1,3,2}$, Xiaoyue Chen ${ }^{1,3,2}$ and Anchun Cheng ${ }^{1,3,2^{*}}$

\begin{abstract}
Background: MicroRNAs (miRNAs) is increasingly recognized as an important element in regulating virus-host interactions. Our previous results showed that cellular miR-30a-5p was significantly downregulated after duck enteritis virus (DEV) infection cell. However, whehter or not the miR-30a-5p is involved in DEV infection has not been known.
\end{abstract}

Methods: Quantitative reverse-transcription PCR (qRT-PCR) was used to measure the expression levels of miRNAs(miR-30a-5p) and Beclin-1 mRNA. The miR-30a-5p - Beclin-1 target interactions were determined by Dual luciferase reporter assay (DLRA). Western blotting was utilized to analyze Beclin-1-mediated duck embryo fibroblast (DEF) cells autophagy activity. DEV titers were estimated by the median tissue culture infective dose $\left(\mathrm{TCID}_{50}\right)$.

Results: The miR-30a-5p was significantly downregulated and the Beclin-1 mRNA was significantly upregulated in DEV-infected DEF cells. DLRA confirmed that miR-30a-5p directly targeted the 3'- UTR of the Beclin-1 gene. Overexpression of miR-30a-5p significantly reduced the expression level of Beclin-1protein $(p<0.05)$, leading to the decrease of Beclin-1-mediated autophagy activity, which ultimately suppressed DEV replication $(P<0.05)$. Whereas transfection of miR-30a-5p inhibitor increased Beclin-1-mediated autophagy and triggered DEV replication during the whole process of DEV infection $(P<0.01)$.

Conclusions: This study shows that miR-30a-5p can inhibit DEV replication through reducing autophagy by targeting Beclin-1. These findings suggest a new insight into virus-host interaction during DEV infection and provide a potential new antiviral therapeutic strategy against DEV infection.

Keywords: Duck enteritis virus, Autophagy, miR-30a-5p, Beclin-1

\footnotetext{
* Correspondence: jiary@sicau.edu.cn; chenganchun@vip.163.com

${ }^{1}$ Research Center of Avian Disease, College of Veterinary Medicine of Sichuan Agricultural University, Wenjiang District, Chengdu 611130, Sichuan Province,

China

Full list of author information is available at the end of the article
}

(c) The Author(s). 2019 Open Access This article is distributed under the terms of the Creative Commons Attribution 4.0 International License (http://creativecommons.org/licenses/by/4.0/), which permits unrestricted use, distribution, and reproduction in any medium, provided you give appropriate credit to the original author(s) and the source, provide a link to the Creative Commons license, and indicate if changes were made. The Creative Commons Public Domain Dedication waiver (http://creativecommons.org/publicdomain/zero/1.0/) applies to the data made available in this article, unless otherwise stated. 


\section{Background}

Duck enteritis virus (DEV) is the causative pathogen of duck viral enteritis disease, causing considerable economic losses in the duck industry due to high mortality and low egg production $[1,2]$. In addition, DEV can cause variable morbidity and mortality in geese, swans and other wild waterfowl and poses a severe threat to waterfowl groups [3-5]. DEV is classified into the family Herpesviridae, subfamily Alphaherpesvirinae, genus Mardivirus and anatid herpesvirus $I$ [6]. Its genome is a linear double-stranded DNA molecule that is composed of a unique long region (UL) and a unique short region (US) flanked by a short internal repeat sequence (IRS) and a short terminal repeat sequence (TRS) [7-10].

Autophagy is an essential self-digestion process that degrades protein and waste in cells to maintain cellular metabolic balance and homeostasis [11, 12]. Growing evidence has shown that viral infection can induce cellular autophagy. For example, some viruses, such as Newcastle disease virus (NDV) [13], classical swine fever virus (CSFV) [14], porcine circovirus type 2 (PCV2) [15], porcine reproductive and respiratory syndrome virus (PRRSV) [16], dengue virus, foot-and-mouth disease virus (FMDV) and varicella-zoster virus (VZV) [17], can induce cell autophagy to enhance their replication. However, autophagy can suppress viral replication and eliminate viral infection $[18,19]$. For example, cellular autophagy can inhibit replication of vesicular stomatitis virus (VSV) by regulating the P13K/AKT signaling pathway [20]. Recent research has reported that DEV induces autophagy to enhance its replication in duck embryo fibroblast (DEF) cells [21]. Nevertheless, the regulatory relationship of autophagy remains poorly understand.

MicroRNAs (miRNAs) are important small (18-24 nt), noncoding, endogenous RNAs that can negatively regulate gene expression by binding fully or partially to the 3 '-untranslated region (3'-UTR) [22, 23]. Accumulating evidence has demonstrated that miRNAs participate in a wide range of biological processes, including cellular proliferation, differentiation, signal transduction, metabolism apoptosis and cellular autophagy [24-27], and play important roles in regulating virus-host interactions [28-30]. Our previous high-throughput sequencing results revealed that 13 cellular miRNAs (mir-125-2-3p, mir-124a-3p, mir-215-5p, mir-29b-3p, etc) were significantly upregulated and 25 miRNAs (mir-1a-3p, mir133a-5p, miR-30a-5p, miR-16c-5p, etc) were significantly downregulated after $\mathrm{CHv}$ infection [31]. Therefore, we speculate that these miRNAs may play crucial roles in DEV infection.

In this study, we first confirmed that miR-30a-5p directly targeted the 3 '-UTR of the Beclin-1 mRNA. Further study showed that overexpression of miR-30a-5p inhibited DEV replication by downregulating Beclin-1- mediated autophagy in DEF cells. miR-30a-5p inhibitor triggered DEV replication, suggesting that miR-30a-5p palys important roles in the regulation of DEV-induced autophagy and viral proliferation. These data provide a basis for further understanding miRNAs' regulatory roles in cellular autophagy and should contribute to the development of anti-DEV drugs.

\section{Methods}

\section{Virus, cells, miRNA mimic and antibodies}

The DEV CHv (Chinese virulent strain) (accession No. JQ647509) and mouse anti-UL41 serum were provided by the Avian Diseases Research Center, College of Veterinary Medicine, Sichuan Agricultural University. Duck embryo fibroblast (DEF) cultures were prepared from 10-day-old duck embryos for the propagation of $\mathrm{CHv}$. The study was approved by the Animal Ethics Committee of Sichuan Agricultural University (approval No. XF2016-17). Cell monolayers were cultured in Dulbecco's Modified Eagle's Medium (DMEM, Gibco, Grand Island, NY USA) supplemented with $10 \%$ fetal bovine serum (FBS, Gibco, USA) and $1 \%$ penicillin-streptomycin (Gibco, USA) at $37^{\circ} \mathrm{C}$ in a $5 \% \mathrm{CO}_{2}$ atmosphere. The miR-30a-5p mimic, mimic negative-control (mimic-NC), miR-30a-5p inhibitor and inhibitor-NC were synthesized by Ribobio (Guangzhou, China) and transfected into cells at a final concentration of $100 \mathrm{nM}$.

\section{Quantitative real-time RT-PCR}

Stem-loop qRT-PCR and general qRT-PCR methods were used to measure the expression levels of miRNAs and Beclin-1 mRNA, respectively. Total RNA from DEV-infected and uninfected DEF cells was extracted with TRIzol reagent (TIANGEN Biotech, Beijing) and quantified using a spectrophotometer (NanoDrop 2000). RNA (1000 ng) was reverse-transcribed to cDNA, and then $2 \mu \mathrm{l} \mathrm{cDNA}$ was used for real-time PCR amplification according to the kit manufacturer's (Thermo) instructions. The primers are listed in Table 1. Relative expression levels of miRNA and Beclin-1 mRNA were calculated using the $2^{-\Delta \Delta \mathrm{Ct}}$ method. U6 and $\beta$-actin were used as respective endogenous controls.

\section{Vector constructs and luciferase assay}

MiR-30a-5p was predicted to target the DEF Beclin-1 3'UTR (nt 136,000-145,890) according to RNAhybrid and PITA software. The Beclin-1 3'UTR (nt 136,085136,248), including the predicted miR-30a-5p binding site, was synthesized by TsingKe (Chengdu, China) and cloned into a pmirGLO vector (Promega, Madison, WI, USA) with SacI and XhoI sites, resulting in pmirGLOWT-Beclin-1. Accordingly, the mutant 3'UTR of the Beclin-1 vector was constructed and named pmirGLOMU-Beclin-1. For the luciferase assay, COS7 cells were 
Table 1 Primers for analysis of gene expression by qRT-PCR

\begin{tabular}{|c|c|}
\hline Primers & Sequence \\
\hline RT-miR-146b-5p & GTCGTATCCAGTGCGTGTCGTGGAGTCGGCAATTGCACTGGATACGACAACGCCTA \\
\hline RT-miR-125b-5p & GTCGTATCCAGTGCGTGTCGTGGAGTCGGCAATTGCACTGGATACGACCACAAGTT \\
\hline RT-miR-30a-5p & GTCGTATCCAGTGCGTGTCGTGGAGTCGGCAATTGCACTGGATACGACAGCTTCCA \\
\hline RT-miR-27b-3p & GTCGTATCCAGTGCGTGTCGTGGAGTCGGCAATTGCACTGGATACGACGCAGAACT \\
\hline RT-miR-16c-5p & GTCGTATCCAGTGCGTGTCGTGGAGTCGGCAATTGCACTGGATACGACCTCCAGTA \\
\hline RT-miR-130b-3p & GTCGTATCCAGTGCGTGTCGTGGAGTCGGCAATTGCACTGGATACGACACGCCCTT \\
\hline miR-146b-5p (F) & GCCGTGAGAACTGAATTCCATA \\
\hline miR-125b-5p (F) & GCCGTCCCTGAGACCCTAA \\
\hline miR-30a-5p (F) & GCCGTGTAAACATCCTTGACTG \\
\hline $\operatorname{miR}-27 b-3 p(F)$ & GCCGTTCACAGTGGCTAAG \\
\hline $\operatorname{miR}-16 c-5 p(F)$ & GCCGTAGCAGCACGTAAATA \\
\hline miR-130b-3p (F) & GCCGCAGTGCAATAATGAAA \\
\hline UR-primer & CAGTGCGTGTCGTGGAGT \\
\hline U6 (F) & CTCGCTTCGGCAGCACA \\
\hline U6 (R) & GCGTGTCATCCTTGCGC \\
\hline Beclin-1 (F) & AAGAGGTGCCTGGAGATCCT \\
\hline Beclin-1 (R) & CGTCCTCCAGCTCCTGAATC \\
\hline$\beta$-Actin (F) & CCGGGCATCGCTGACA \\
\hline$\beta$-Actin (R) & GGATTCATCATACTCCTGCTITGCT \\
\hline
\end{tabular}

seeded in 96-well plates and cotransfected with miR30a-5p mimic, miR-NC, pmirGLO-WT-Beclin-1 and pmirGLO-MU-Beclin-1 with Lipofectamine 3000 (Invitrogen, Carlsbad, CA, USA). We performed a sitedirected DLRA, and luciferase activity was measured at $36 \mathrm{~h}$ posttransfection according to the manufacturer's protocol (Promega, Madison, WI, USA).

\section{Western blot analysis}

The synthetic miR-30a-5p mimic, miR-NC, miR-30a-5p inhibitor and inhibitor-NC were transfected into DEF cells with Lipofectamine 3000 (Invitrogen) according to the manufacturer's protocol. Meanwhile, the blank group (without) was set as the control group. Cells were infected with DEV at a multiplicity of infection (MOI) of 1.0 for $36 \mathrm{~h}$. The cells were harvested and washed 3 times with cold PBS. The PBS was decanted and then $150 \mu \mathrm{l}$ RIPA lysis buffer (Solarbio, China) and $1.0 \mathrm{mM}$ PSMF were added. After $30 \mathrm{~min}$ on ice and centrifugation at $12,000 \mathrm{~g}$ for $10 \mathrm{~min}, 25 \mu \mathrm{l}$ supernatant was mixed with $25 \mu \mathrm{l} 5 \times$ SDS loading buffer and boiled for $10 \mathrm{~min}$. The protein samples were analyzed by $12 \%$ SDS polyacrylamide gel electrophoresis and transferred to a polyvinylidene difluorride (PVDF) membranes (Millipore, Billerica, MA) by electroelution. Membranes were blocked with 5\% milk-TBS-Tween-20 for $2 \mathrm{~h}$ at room temperature and incubated with rabbit anti-LC3 (Proteintech, 14,600-1-AP), rabbit anti-p62/SQSTM1 (Cell
Signaling Technology, 5114), mouse anti- $\beta$-actin (Proteintech, 60,008-1-Ig), rabbit anti-Beclin-1 (Proteintech, 11,306-1-AP) and anti-CHv (UL41) antibodies overnight at $4{ }^{\circ} \mathrm{C}$. Following incubation with HRP-conjugated goat anti-rabbit or anti-mouse IgG (Biodragon-Immunotech, China) as secondary antibody for $2 \mathrm{~h}$ at $37^{\circ} \mathrm{C}$, the immunoreactive bands were detected using an enhanced chemiluminescence kit (Solarbio, China). The amount of proteins was quantified by densitometry and normalized to $\beta$-actin, an internal standard.

\section{Flow cytometry assay}

DEF cells were seed in a 6-well plate at adensity of $1 \times$ $10^{6}$ cells per well. Cells were pretreated with control (without), miR-30a-5p mimic, miR-NC, miR-30a-5p inhibitor and inhibitor-NC for $4 \mathrm{~h}$ and then infected with $\operatorname{DEV}(\mathrm{MOI}=1.0)$ for $36 \mathrm{~h}$. The cells were stained with Annexin V-fluorescein isothiocyanate (V-FITC) (BD Pharmingen, USA) and propidium iodide (PI) (BD Pharmingen, USA) according to the manufacturer's instructions, and the percentage of apoptotic cells was assayed by flow cytometry (FCM).

\section{Cell viability analysis}

miRNA toxicity tests were performed using the MTT assay kit (Sangon Biotech, Shanghai, China) according to the manufacturer's instructions. In brief, DEF cells were seeded in 96-well culture plates at a density of $1 \times 10^{5}$ 
cells per well. Cells were pretreated with control, miR-30a$5 p$ mimic, miR-NC, miR-30a-5p inhibitor and inhibitor$\mathrm{NC}$ for $4 \mathrm{~h}$ and then cultured in DMEM for $36 \mathrm{~h}$, the cells were incubated in $100 \mu \mathrm{l}$ fresh culture medium containing MTT $\left(0.5 \mathrm{mg} \mathrm{mL}^{-1}\right)$ for $4 \mathrm{~h}$ at $37^{\circ} \mathrm{C}$. The medium was replaced by $100 \mu \mathrm{l}$ formazan solubilization solution, and the absorbance was measured at $570 \mathrm{~nm}$ using a microplate reader (Bio-Rad).

\section{DEV replication analysis}

DEV viral copies were detected using qRT-PCR methods. DEF cells were seed in a 6-well plate at adensity of $1 \times 10^{6}$ cells per well. Cells were pretreated with control, miR-30a-5p mimic, miR-NC, miR-30a-5p inhibitor and inhibitor-NC for $4 \mathrm{~h}$ and then infected with DEV $(\mathrm{MOI}=1.0)$. The cells were collected at the indicated times and stored at $-80^{\circ} \mathrm{C}$ for subsequent experiments. The DEV absolute quantitative curve was created as previously described methods [32, 33].

DEV titers were estimated by the median tissue culture infective dose $\left(\mathrm{TCID}_{50}\right)$. DEF cells were seed in 96-well plates at adensity of $1 \times 10^{5}$ cells per well. Cells were pretreated with control, miR-30a-5p mimic, miR-NC, miR$30 \mathrm{a}-5 \mathrm{p}$ inhibitor and inhibitor-NC for $4 \mathrm{~h}$ and then infected with DEV collected at the indicated times above. The plates were incubated for 5 days at $37^{\circ} \mathrm{C}$ in a $5 \% \mathrm{CO}_{2}$ atmosphere. Cell pathological changes were observed under a light microscope and recorded. Viral titers were measured according to the Reed-Muench method [34].

\section{Statistical analysis}

Each assay was performed in three independent experiments. All experimental results are expressed as the mean \pm standard deviation (mean $\pm \mathrm{SD}$ ) and were analyzed by the software GraphPad Prism (version 7.0). The statistical significance was assessed using Student's ttest. ${ }^{*} p<0.05$ and ${ }^{* *} p<0.01$ indicate significance.

\section{Results \\ DEV infection induces downregulation of miR-30a-5p and promotes Beclin-1 mRNA expression}

According to our previous high-throughput sequencing results [31], six miRNAs were chosen and detected using the stem-loop qRT-PCR method. The results showed that the expression levels of miR-30a-5p and miR-16c$5 p$ were significantly downregulated in DEV-infected DEF cells at 24 hpi $(P<0.01)($ Fig. $1 \mathrm{a})$, and there were no obvious changes in the remaining four miRNAs (miR-146b-5p, miR-27b-3p, miR-130b-3p and miR125b-5p) compared with uninfected cells (Fig. 1a). We detected the expression levels of miR-30a-5p and miR$16 \mathrm{c}-5 \mathrm{p}$ at $4,12,24,36$ and 48 hpi in DEV-infected group and uninfected group respectively. We found that the expression levels of mir-30a-5p and mir-16c-5p in the uninfected group were 2.5 and 2.2 times as high as those in the infected group at 36 hpi respectively (Fig. 1b, c). In addition, qRT-PCR results showed that the expression level of Beclin-1 was upregulated in DEV-infected DEF cells and was 2.1- and 2.4-fold higher compared with the uninfected group at $36 \mathrm{hpi}$ and $48 \mathrm{hpi} \mathrm{(Fig.} \mathrm{1d).}$

\section{Beclin-1 is a target of miR-30a-5p in DEF cells}

A DLRA showed that pmirGLO-WT-Beclin-1 was significantly repressed by miR-30a-5p compared to the mimic-NC group $(p<0.01)$ (Fig. 2a, b). To further explore whether the downregulation of targets by miR$30 \mathrm{a}-5 \mathrm{p}$ was binding site-dependent, the binding sites of Beclin-1 were mutated to make the construct pmirGLOMU-Beclin-1 vector (Fig. 2a). As expected, miR-30a-5p lost its repression effect on the mutant vector pmirGLOMU-Beclin-1 (Fig. 2b). These results indicated that miR$30 \mathrm{a}-5 \mathrm{p}$ can directly target the DEF Beclin-1 mRNA at a 8 -nucleotide complementary seed sequence.

\section{miR-30a-5p suppresses Beclin-1 expression and autophagy is induced by DEV}

To further explore whether therer is the negative regulation relationship between miR-30a-5p and Beclin-1 in DEV-infected DEF cells, DEF cells were transfected with control, miR-30a-5p mimic, miR-NC, miR-30a-5p inhibitor and inhibitor-NC for $4 \mathrm{~h}$ and then infected with DEV $(\mathrm{MOI}=1.0)$ for $36 \mathrm{~h}$. The mRNA expression levels of miR-30a-5p and Beclin-1 were evaluated by qRTPCR. As expected, Transfection of the miR-30a-5p mimic significantly increased the miR-30a-5p expression and decreased the mRNA level of Beclin-1. Consistently, miR-30a-5p inhibitor had the opposite effects on expression in miR-30a-5p and Beclin-1 $(P<0.01)$ (Fig. 2c, d).

Next, we observed the effect of miR-30a-5p on autophagy. Western blot analysis showed that miR-30a-5p overexpression significantly decreased Beclin- 1 protein expression. The ratio of of LC3-II/LC3-I was significantly downregulated and the $\mathrm{p} 62$ protein level was significantly upregulated in the miR-30a-5p group, suggesting that autophagy was inhibited by miR-30a-5p regulating Beclin-1 (Fig. 3a, b). While the miR-30a-5p inhibitor increased Beclin-1 protein level and decreased p62 expression. An increaed ratio of LC3-II/LC3-I was observed for miR-30a$5 \mathrm{p}$ inhibitor-treated group compared to inhibitor-NC group, indicating that autophagy activity was promoted (Fig. 3c, d). Specific viral proteins with UL41 antibody indicated the process of viral infection. These results revealed that the miR-30a-5p inhibited autophagy by regulating Beclin-1in DEV-infected cells.

\section{miR-30a-5p promotes DEV-induced DEF cell apoptosis}

A FCM was used to detect DEV-induced DEF cell apoptosis after transfecting control, miR-30a-5p mimic, miR- 


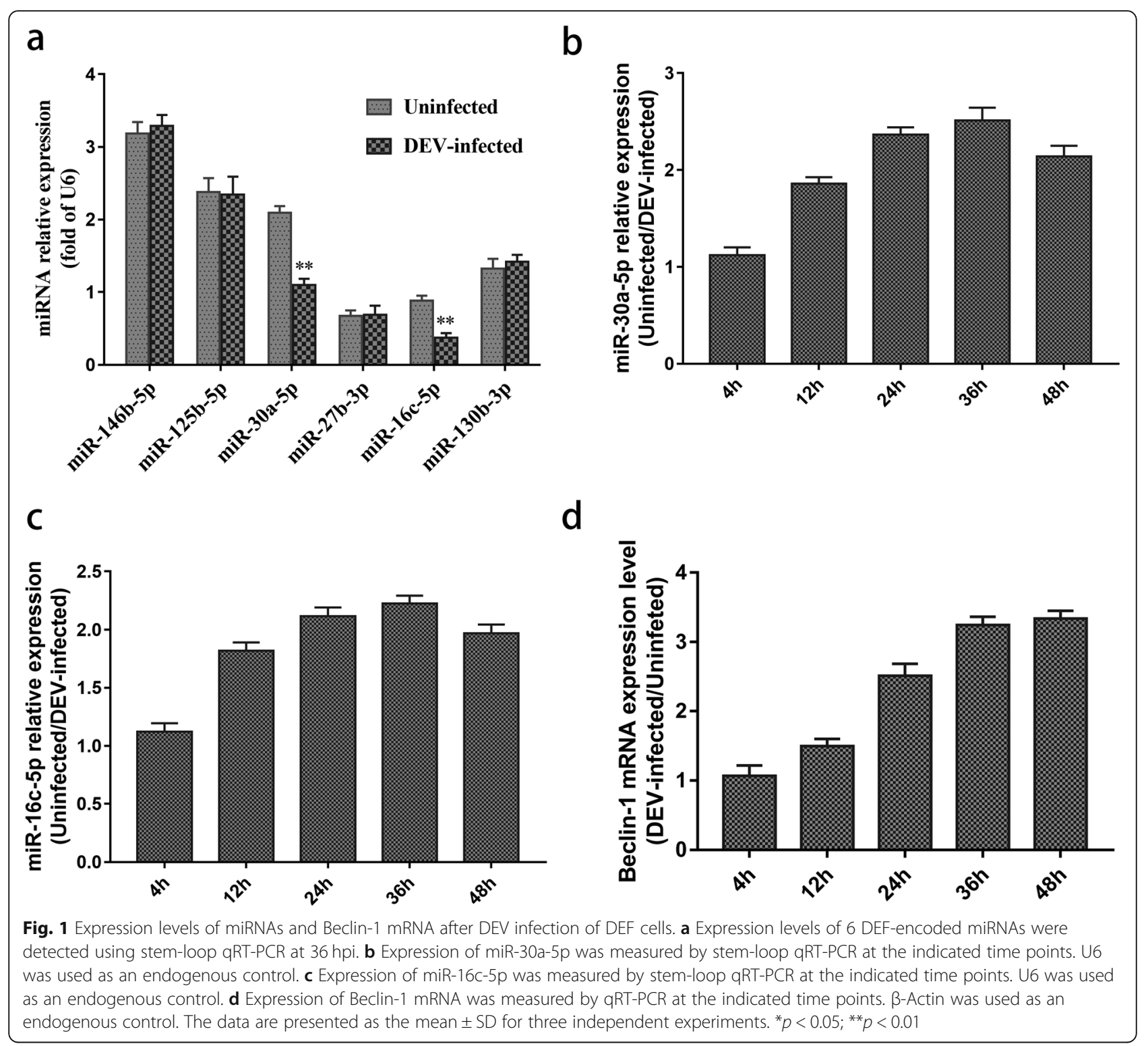

NC, miR-30a-5p inhibitor and inhibitor-NC. The results revealed that the percentage of apoptotic DEF cells was significantly increased at $36 \mathrm{hpi}$ in the miR-30a-5p mimic group. However, the transfection of miR-30a-5p inhibitor significantly decreased the percentage of apoptotic cells in DEVinfected cells (Fig. 4a). These results showed that miR-30a5 p promoted DEV-induced apoptosis of DEF cells.

\section{Cell viability unaffected by miRNAs treatment}

The miRNAs might have influenced cell viability and affected our results. The effects on cell viability of the miRNAs used in this study were measured by MTT assays. The viability of treated cells was almost equal to that of control cells, so the miRNAs treatments did not affect DEF cell viability (Fig. 4b).
miR-30a-5p overexpression reduces DEV replication

To identify the potential function of miR-30a-5p in the viral replication process, DEF cells were transfected with control, miR-30a-5p mimic, miR-NC, miR-30a-5p inhibitor and inhibitor-NC for $4 \mathrm{~h}$ and then infected with DEV $(M O I=1.0)$. The genome copy number of DEV was measured by qRT-PCR at the indicated time points, and overexpression of miR-30a-5p strongly suppressed DEV replication at 12, 24, 36, 48 and $60 \mathrm{hpi}$, while the miR-30a-5p inhibitor significantly triggered DEV replication at the same time points (Fig. 4c).

Viral yields were determined by $\mathrm{TCID}_{50}$ at the indicated time points, and titers of progeny viruses collected from miR-30a-5p mimic group were lower than from control cells at 24, 36, 48 and 60 hpi. While viral titers 


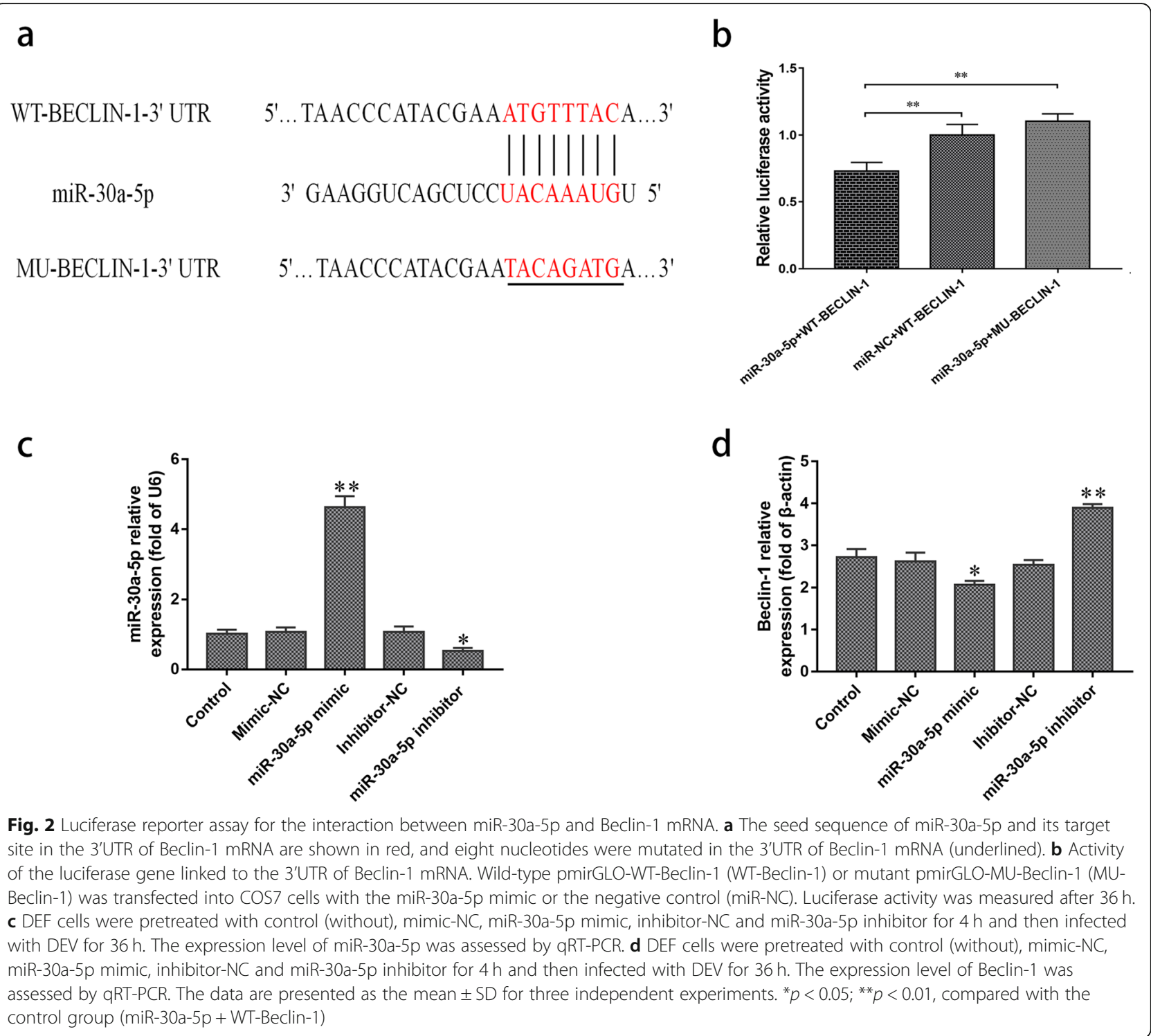

in miR-30a-5p inhibitor group were significantly upregulated compared with the control group (Fig. 4d).

\section{Discussion}

There have been several reports about miR-30a-5p target genes and their involvement in pathophysiological processes. For example, miR-30a-5p promotes the replication of porcine circovirus type 2 through enhancing autophagy by targeting 14-3-3 [15]. MiR-30a-5p downregulation contributes to the chemoresistance of osteosarcoma cells by activating Beclin-1-mediated autophagy [35]. The expression of miR-30a-5p is significantly downregulated in human colorectal cancer (CRC) tissues and CRC cell lines and may be a potential candidate target for CRC therapy [36]. Low expression of miR-30a-5p induces the proliferation and invasion of oral cancer by promoting the expression of FAP (Homo sapiens fibroblast activation protein $\alpha$ ), and miR-30a-5p might be a new therapeutic target for oral cancer treatment [37]. In our previous study, miRNA expression profiles of virus and host were determined and analyzed in virulent DEV-infected DEF cells. The expression level of miRNA-30a-5p was significantly downregulated during the whole process of DEV infection [31], and similar results were confirmed by stem-loop qRT-PCR in this study (Fig. 1b). We speculate that miR-30a-5p plays an important role in regulating host-virus interactions.

Autophagy is an essential pathway for cellular homeostasis. Many studies have confirmed that some viruses can induce cells manipulate autophagy to promote their survival and replication [38, 39]. Examples include hepatitis C virus [40], egg drop syndrome virus (EDSV) [41], avian reovirus [42] and influenza A virus [43]. Rrecent study demonstrated that autophagy induced by DEV 

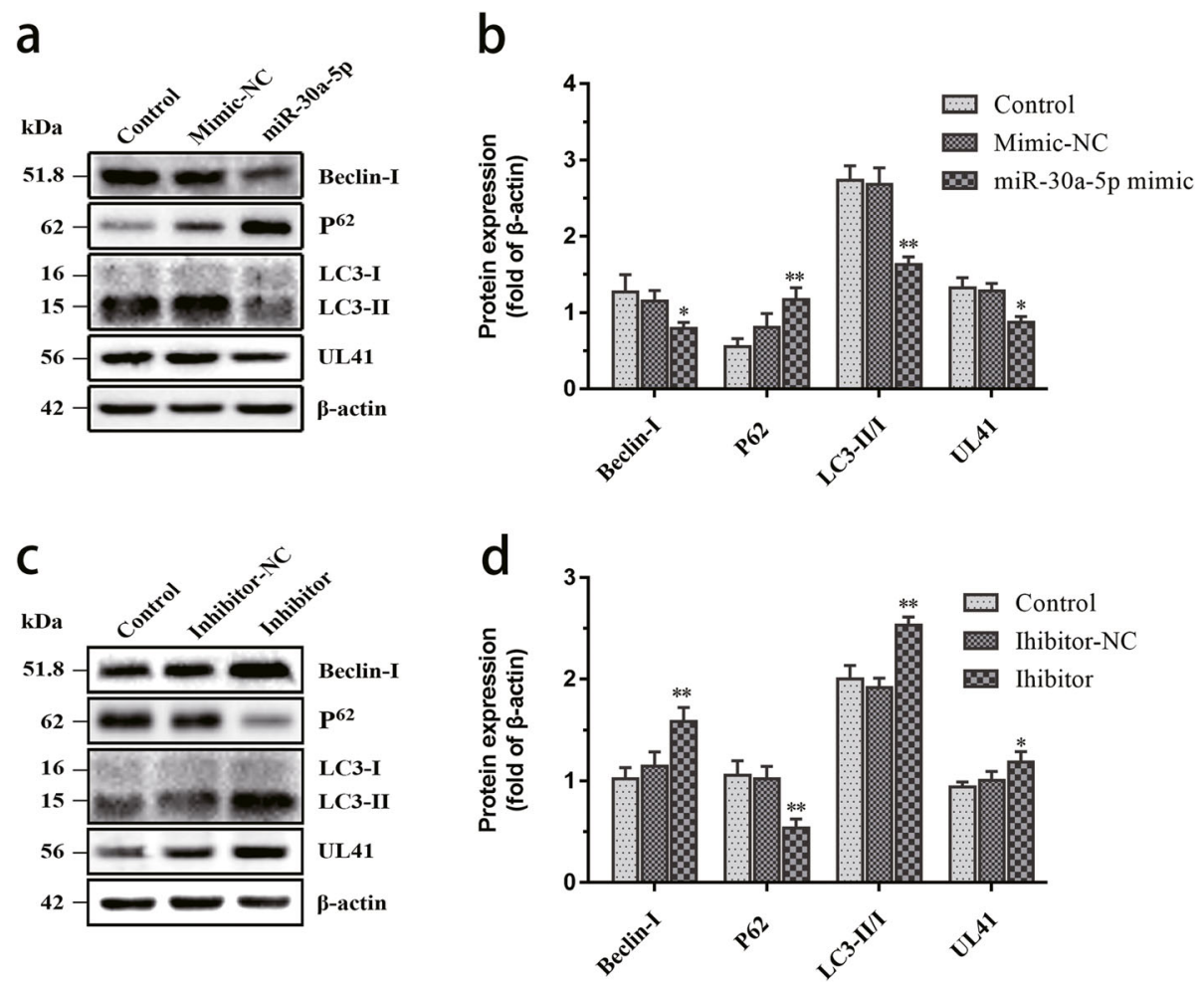

Fig. 3 miR-30a-5p overexpression suppresses Beclin-1 expression and DEV-induced autophagy. a DEF cells were pretreated with control (without), mimic-NC and miR-30a-5p mimic for $4 \mathrm{~h}$ and then infected with DEV. Cells were lysed and blotted with antibodies against Beclin-1, p62, LC3, $\beta-$ actin and UL41 at $36 \mathrm{hpi}$. $\mathbf{b}$ The optical densities of each protein band from (a) were measured by densitometric scanning, and the optical

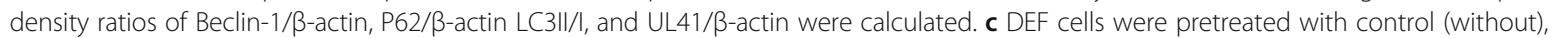
inhibitor-NC and miR-30a-5p inhibitor for $4 \mathrm{~h}$ and then infected with DEV. Cells were lysed and blotted with antibodies against Beclin-1, p62, LC3, $\beta$-actin and UL41 at 36 hpi. d The optical densities of each protein band from (c) were measured by densitometric scanning, and the optical density ratios of Beclin-1/ $\beta$-actin, P62/ $\beta$-actin LC3II/I, and UL41/ $\beta$-actin were calculated. The data are presented as the mean \pm SD for three independent experiments. ${ }^{*} p<0.05 ;{ }^{* *} p<0.01$, compared with the control group

infection positively promotes viral replication [21]. However, the regulating relationship of autophagy in DEVinfected DEF cells is still unclear. In this study, our data showed that the expression of miR-30a-5p was downregulated and that Beclin-1 was upregulated after $\mathrm{CHv}$ infection of DEF cells. The Beclin-1 gene is recognized as a critical regulatory gene during autophagosome formation and maturation [44] and plays important roles in the replication of some viruses. For example, the replication of these three viruses (NDV, CSFV and DEV) was inhibited by siRNA knockdown of Beclin-1 gene level, which is required for autophagy [13, 14, 21]. Previous studies have demonstrated that miR-30a-5p regulates autophagy activity by targeting Beclin-1 mRNA [45-47]. Therefore, we speculated that there is the negative regulation relationship between Beclin-1 and endogenous miR-30a-5p in DEV-infected DEF cells. To confirm the regulation of miR-30a-5p on Beclin-1, bioinformatics analysis was performed using RNAhybrid software [31]. The results showed that miR-30a-5p was predicted to target the 3'-UTR region of Beclin-1. DLRA confirmed that overexpression of miR-30a-5p markedly reduced the luciferase level from Beclin-1 (Fig. 2a, b).

Western blot analysis demonstrated that overexpression of miR-30a-5p decreased decreased Beclin-1 protein level and the ratio of of LC3-II/LC3-I, enhanced the p62 protein level, which are related to autophagy. The expression of UL41 protein decreased (Fig. 3a, b). Whereas miR-30a-5p inhibitor attenuated DEV-induced cell autophagy and reversed the effect of miR-30a-5p. Both Beclin-1 and the ratio of LC3-II/LC3-I significantly increased in miR-30a-5p inhibitor group. The p62 protein level decreased and the expression of UL41 protein increased (Fig. 3c, d). The TCID 50 and the viral copy test confirmed that DEV titers were significantly decreased in the miR-30a-5p mimic group compared with control group. Whereas transfection of miR-30a-5p inhibitor promoted DEV replication during the whole process of DEV infection (Fig. 4c and d). Our results were consistent with a previous report on autophagy induced by DEV [21], suggesting a key role for the miR-30a-5p/autophagy loop in DEV infection. These results strongly 


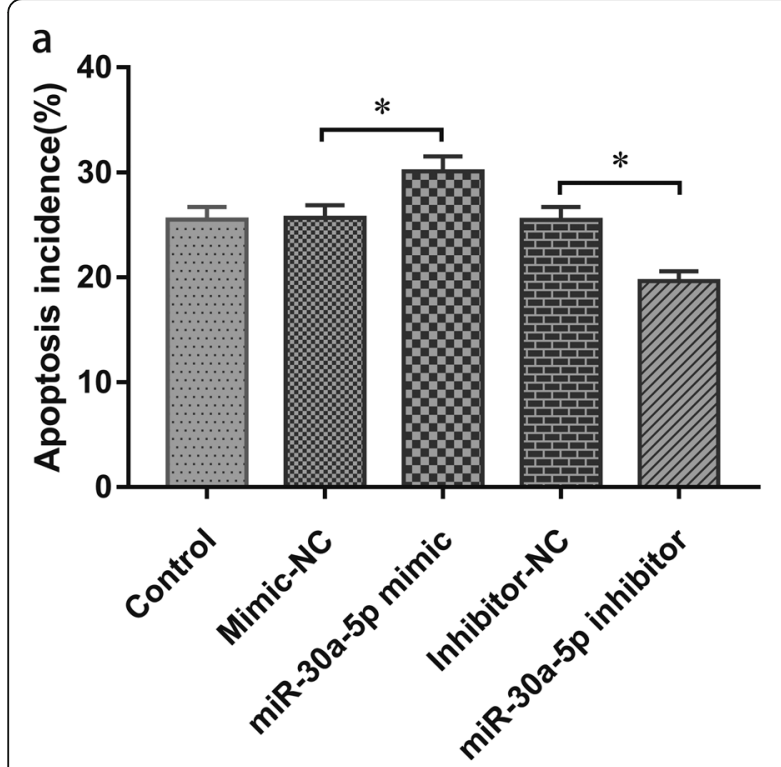

b

C

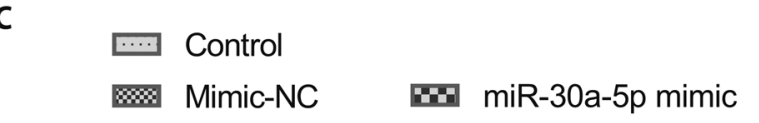

d
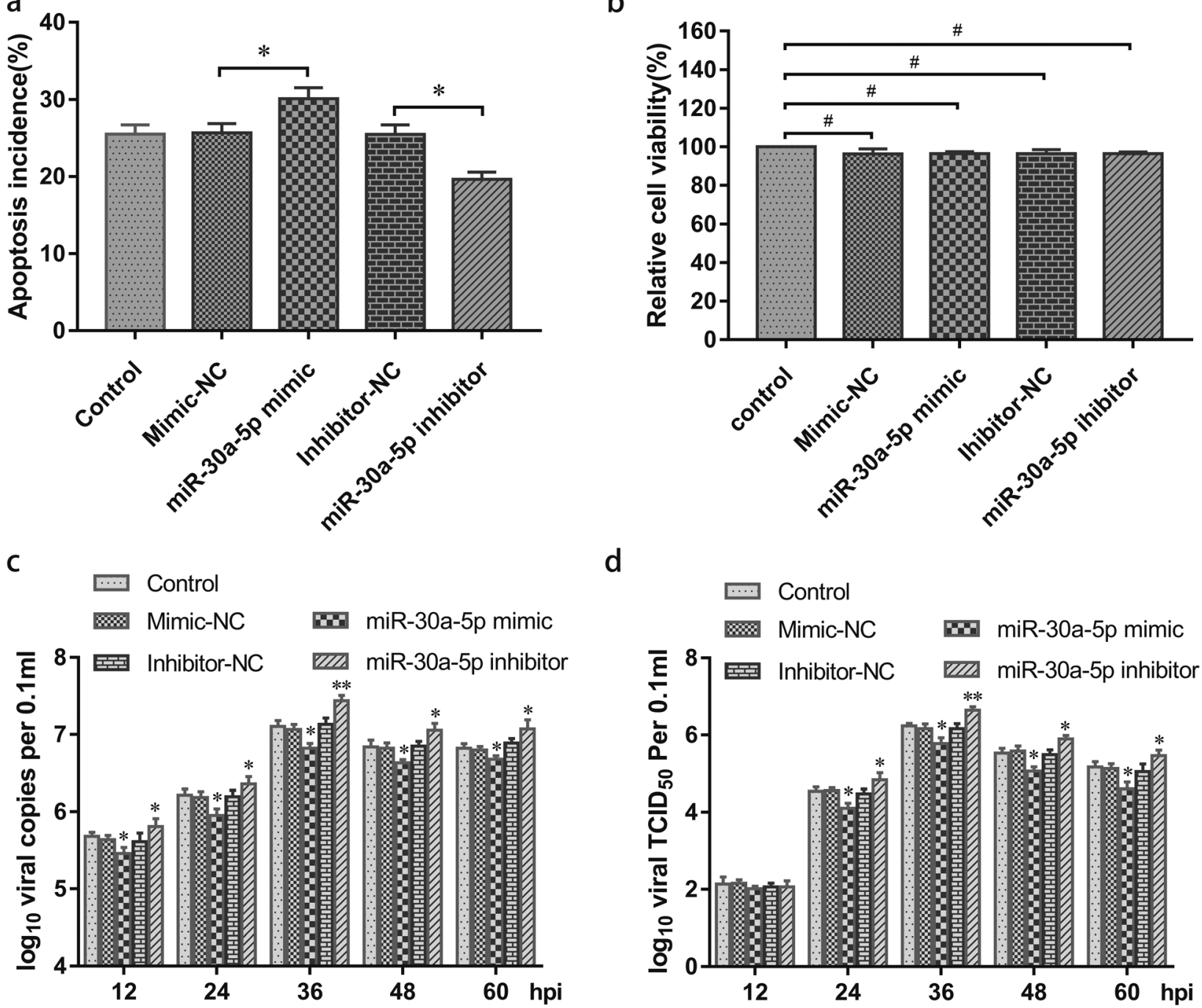

Fig. 4 miR-30a-5p overexpression reduces DEV replication in DEF cells. a DEF cells were pretreated with control (without), mimic-NC, miR-30a-5p mimic, inhibitor-NC and miR-30a-5p inhibitor for $4 \mathrm{~h}$ and then infected with DEV for $36 \mathrm{~h}$. Apoptosis was analyzed by Annexin V-FITC/PI staining using flow cytometry. $\mathbf{b}$ Changes in DEF viability following treatment with control (without), mimic-NC, miR-30a-5p mimic, inhibitor-NC and miR$30 \mathrm{a}-5 \mathrm{p}$ inhibitor for $4 \mathrm{~h}$ and then cultured in DMEM at $37^{\circ} \mathrm{C}$. The cell viability were tested by MTT assay kit at $36 \mathrm{~h}$. $\mathbf{c}$ DEF cells were pretreated with control (without), mimic-NC, miR-30a-5p mimic, inhibitor-NC and miR-30a-5p inhibitor for $4 \mathrm{~h}$ and then infected with DEV. Viral copies were determined at the indicated time points. $\mathbf{d}$ DEF cells were pretreated with control (without), mimic-NC, miR-30a-5p mimic, inhibitor-NC and miR30a-5p inhibitor for $4 \mathrm{~h}$ and then infected with DEV, and viral yields $\left(T_{C} \mathrm{D}_{50}\right.$ per $\left.0.1 \mathrm{ml}\right)$ were determined at the indicated time points. The data are presented as the mean \pm SD for three independent experiments. ${ }^{*} p<0.05$; ${ }^{* *} p<0.01$, compared with the control group. "\# " indicates no significant difference, $P>0.05$

suggested that overexpression of miR-30a-5p decreased DEV replication by suppressing Beclin-1-mediated autophagy. Therefore, it is reasonable to conclude that downregulation of miR-30a-5p contributes to DEV replication by upregulating Beclin-1-mediated autophagy.

Apoptosis regulates embryonic development, cell turnover, and the immune response against tumor or virusinfected cells $[48,49]$. Virus-induced cell apoptosis is involved in the pathogenesis of many viral infections [50,51]. Our laboratory has discovered that DEV can induce apoptosis in the thymus, spleen and pancreatic lymphocytes of adult ducks and can cause apoptosis in DEFs in vitro $[52,53]$, and further confirmed that the mRNA levels and enzymatic activities of caspase- 3 , caspase- 7 and caspase- 9 were significantly increased during DEV-induced cell apoptosis [53]. Recent study has also reported miR-30a-5p can promote doxorubicin-induced osteosarcoma cell apoptosis by increasing the expression of cleaved caspase3 , and further certified that miR-30a-5p promotes chemotherapy-induced osteosarcoma cell apoptosis via repressing Beclin-1-mediated osteosarcoma autophagy [35]. In our study, flow cytometry demonstrated that 
overexpression of miR-30a-5p enhanced DEV-induced cell apoptosis (Fig. 4a). Nevertheless, miR-30a-5p inhibitor attenuated DEV-induced cell apoptosis and reversed the effect of miR-30a-5p (Fig. 4a). However, whehter or not the miR-30a-5p increased DEV-induced cell apoptosis by suppressing Beclin-1-mediated autophagy requires further confirmation.

\section{Conclusions}

The results of this study showed that the miR-30a-5p/autophagy loop plays an important role in DEV infection, and this is the first report of miR-30a-5p in herpesvirusinduced autophagy. Our work confirms the existence of a novel regulatory pathway controlled by miR-30a-5p and its direct target, Beclin-1, that regulates DEV replication in DEFs. Therefore, miR-30a-5p and its target gene pathway may represent new treatment methods for duck viral enteritis disease.

\section{Abbreviations}

CHv: Chinese virulent; CSFV: Classical swine fever virus; DEV: Duck enteritis virus; EDSV: Egg drop syndrome virus; IRS: Inverted repeated sequences; NDV: Newcastle disease virus; PCV2: Porcine circovirus type 2; PRRSV: Porcine reproductive and respiratory syndrome virus; qRT-PCR: Quantitative real-time reverse transcriotion PCR; TRS: terminal repeated sequences; UL: Unique long region; US: Unique short region; VZV: Varicella-Zoster virus

\section{Acknowledgments}

We would like to thank all members of Avian Disease Research Center for their contributions to this study.

\section{Authors' contributions}

Conceived and designed the experiments: RYJ XLW. Performed the experiments: XLW. Analyzed the data: RYJ, MSW, SC, MFL, DKZ, XXZ, QY, YW, ZQY, SQZ, JH, YLY, LCP, BT, MUR, XYC, ACC. Contributed reagents and materials: LZ, YYL. Wrote the paper: XLW, RYJ. All authors read and approved the final manuscript.

\section{Funding}

This work was supported by the National Natural Science Foundation of China (31872475), Sichuan Veterinary Medicine and Drug Innovation Group of China Agricultural Research System (CARS-SVDIP), China Agricultural Research System (CARS-42-17), and Sichuan Province Research Program (2017JY0014).

\section{Availability of data and materials}

The datasets used or analysed during this study are included within the article.

\section{Ethics approval and consent to participate}

The study was approved by the Animal Ethics Committee of Sichuan Agricultural University (approval No. XF2016-17).

\section{Consent for publication}

Not applicable.

\section{Competing interests}

The authors declare that they have no competing interests.

\section{Author details}

${ }^{1}$ Research Center of Avian Disease, College of Veterinary Medicine of Sichuan Agricultural University, Wenjiang District, Chengdu 611130, Sichuan Province, China. ${ }^{2}$ Institute of Preventive Veterinary Medicine, Sichuan Agricultural University, Wenjiang District, Chengdu 611130, Sichuan Province, China. ${ }^{3}$ Key Laboratory of Animal Disease and Human Health of Sichuan Province, Wenjiang District, Chengdu 611130, Sichuan Province, China.
Received: 7 August 2019 Accepted: 11 November 2019

Published online: 26 November 2019

\section{References}

1. Wang G, Qu Y, Wang F, Hu D, Liu L, Li N, et al. The comprehensive diagnosis and prevention of duck plague in Northwest Shandong province of China. Poult Sci. 2013:92(11):2892-8.

2. Dhama K, Kumar N, Saminathan M, Tiwari R, Karthik K, Kumar MA, et al. Duck virus enteritis (duck plague) - a comprehensive update. Vet Q. 2017; 37(1):57.

3. Kaleta EF, Kuczka A, Kühnhold A, Bunzenthal C, Bönner BM, Hanka K, et al. Outbreak of duck plague (duck herpesvirus enteritis) in numerous species of captive ducks and geese in temporal conjunction with enforced biosecurity (in-house keeping) due to the threat of avian influenza a virus of the subtype Asia H5N1. Dtw Deutsche Tierärztliche Wochenschrift. 2007;114(1):3-11.

4. Keymer IF, Gough RE. Duck virus enteritis (anatid herpesvirus infection) in mute swans (Cygnus Olor). Avian Pathology. 1986;15(1):161-70.

5. Metwally SA SD, Glisson JR, McDougald LR, Nolan, LK, Suarez DL, Nair V, Duck Virus Enteritis (Duck Plague)[M]. In: Diseases of Poultry, 13th Edition 2013:431-40.

6. King AMQ. Virus taxonomy: classification and nomenclature of viruses : ninth report of the international committee on taxonomy of viruses: Elsevier/academic press; 2012.

7. Li Y, Huang B, Ma X, Wu J, Li F, Ai W, et al. Molecular characterization of the genome of duck enteritis virus. Virology. 2009;391(2):151-61.

8. Wang J, Höper D, Beer M, Osterrieder N. Complete genome sequence of virulent duck enteritis virus (DEV) strain 2085 and comparison with genome sequences of virulent and attenuated DEV strains. Virus Res. 2011:160(1):316-25.

9. Wu Y, Cheng A, Wang M, Yang Q, Zhu D, Jia R, et al. Complete genomic sequence of Chinese virulent duck enteritis virus. J Virol. 2012;86(10):5965.

10. Wu Y, Cheng A, Wang M, Zhu D, Jia R, Chen S, et al. Comparative genomic analysis of duck enteritis virus strains. J Virol. 2012;86(24):13841-2.

11. Reggiori F. 1. Membrane origin for autophagy. Curr Top Dev Biol. 2006;74:1.

12. Levine B, Klionsky DJ. Development by self-digestion: molecular mechanisms and biological functions of autophagy. Dev Cell. 2004;6(4):463.

13. Sun Y, Yu S, Ding N, Meng C, Meng S, Zhang S, et al. Autophagy benefits the replication of Newcastle disease virus in chicken cells and tissues. J Virol. 2014;88(1):525.

14. Pei J, Zhao M, Ye Z, Gou H, Wang J, Yi L, et al. Autophagy enhances the replication of classical swine fever virus in vitro. Autophagy. 2014; 10(1):93-110

15. Wang $X$, Xu X, Wang W, Yu Z, Wen L, He K, et al. MicroRNA-30a-5p promotes replication of porcine circovirus type 2 through enhancing autophagy by targeting 14-3-3. Arch Virol. 2017;22:1-12.

16. Chen $Q$, Fang L, Wang D, Wang S, Li P, Li M, et al. Induction of autophagy enhances porcine reproductive and respiratory syndrome virus replication. Virus Res. 2012;163(2):650-5.

17. Buckingham EM, Carpenter JE, Jackson W, Zerboni L, Arvin AM, Grose C. Autophagic flux without a block differentiates varicella-zoster virus infection from herpes simplex virus infection. Proc Natl Acad Sci U S A. 2015;112(1):256-61.

18. Gutierrez MG, Master SS, Singh SB, Taylor GA, Colombo MI, Deretic V. Autophagy is a defense mechanism inhibiting BCG and mycobacterium tuberculosis survival in infected macrophages. Cell. 2004;119(6):753-66.

19. Schmid D, Münz C. Innate and adaptive immunity through autophagy. Immunity. 2007;27(1):11-21.

20. Shelly S, Lukinova N, Bambina S, Berman A, Cherry S. Autophagy is an essential component of Drosophila immunity against vesicular stomatitis virus. Immunity. 2009;30(4):588-98.

21. Yin H-C, Zhao L-L, Li S-Q, Niu Y-J, Jiang X-J, Xu L-J, et al. Autophagy activated by duck enteritis virus infection positively affects its replication. J Gen Virol. 2017;98(3):486-95.

22. Bartel DP. MicroRNAs: target recognition and regulatory functions. Cell. 2009;136(2):215.

23. Fasanaro P, Greco S, Ivan M, Capogrossi MC, Martelli F. microRNA: emerging therapeutic targets in acute ischemic diseases. Pharmacol Ther. 2010;125(1):92-104.

24. Cullen BR. Viral and cellular messenger RNA targets of viral microRNAs. Nature. 2009:457(7228):421-5. 
25. Huang Y, Shen XJ, Zou Q, Wang SP, Tang SM, Zhang GZ. Biological functions of microRNAs: a review. J Physiol Biochem. 2011;67(1):129-39.

26. Abeliovich $\mathrm{H}$. Guidelines for the use and interpretation of assays for monitoring autophagy: Haematologica; 2012. 151-75 p.

27. Fu LL, Wen X, Bao JK, Liu B. MicroRNA-modulated autophagic signaling networks in cancer. Int J Biochem Cell Biol. 2012:44(5):733.

28. Yao Y, Smith LP, Nair V, Watson M. An avian retrovirus uses canonical expression and processing mechanisms to generate viral microRNA. J Virol. 2014;88(1):2-9.

29. Grey F. Role of microRNAs in herpesvirus latency and persistence. J Gen Virol. 2015;96(4):739-51.

30. Frappier L. Regulation of herpesvirus reactivation by host microRNAs. J Virol. 2015;89(5):2456.

31. Zhou H, Chen S, Zhou Q, Wei $Y$, Wang M, Jia R, et al. Cross-species antiviral activity of goose Interferons against duck plague virus is related to its positive self-feedback regulation and subsequent interferon stimulated genes induction. Viruses. 2016:8(7):195.

32. Chen S, Zhang W, Zhou Q, Wang A, Sun L, Wang M, et al. Crossspecies antiviral activity of goose interferon lambda against duck plague virus is related to its positive self-regulatory feedback loop. $J$ Gen Virol. 2017:98(6):1455-66.

33. Reed $\amalg$, Muench $H$. A simple method of estimating fifty per cent endpoints. Am J Epidemiol. 1938;27(3):493-7.

34. Wu X, Jia R, Zhou J, Wang M, Chen S, Liu M, et al. Virulent duck enteritis virus infected DEF cells generate a unique pattern of viral microRNAs and a novel set of host microRNAs. BMC Vet Res. 2018;14(1):144.

35. Xu R, Liu S, Chen H, Lao L. MicroRNA-30a downregulation contributes to chemoresistance of osteosarcoma cells through activating Beclin-1mediated autophagy. Oncol Rep. 2016;35(3):1757.

36. Park YR, Kim SL, Lee MR, Seo SY, Lee JH, Kim SH, et al. MicroRNA-30a-5p (miR-30a) regulates cell motility and EMT by directly targeting oncogenic TM4SF1 in colorectal cancer. J Cancer Res Clin Oncol. 2017;143(11):1-13.

37. Ruan P, Tan A, Tao Z. Low expression of miR-30a-5p induced the proliferation and invasion of oral cancer via promoting the expression of FAP. Biosci Rep. 2018;38(1):BSR20171027.

38. Kim HJ, Lee $S$, Jung JU. When autophagy meets viruses: a double-edged sword with functions in defense and offense. Semin Immunopathol. 2010; 32(4):323-41.

39. Jain B, Chaturvedi UC, Jain A. Role of intracellular events in the pathogenesis of dengue; an overview. Microb Pathog. 2014;69-70(1):45-52.

40. Wileman T. Aggresomes and autophagy generate sites for virus replication. Science. 2006:312(5775):875-8.

41. Wang X, Qi X, Yang B, Chen S, Wang J. Autophagy benefits the replication of egg drop syndrome virus in duck embryo fibroblasts. Front Microbiol. 2018:9.

42. Meng $S$, Jiang $K$, Zhang $X$, Zhang M, Zhou Z, Hu M, et al. Avian reovirus triggers autophagy in primary chicken fibroblast cells and Vero cells to promote virus production. Arch Virol. 2012;157(4):661-8.

43. Zhou Z, Jiang X, Liu D, Fan Z, Hu X, Yan J, et al. Autophagy is involved in influenza a virus replication. Autophagy. 2009;5(3):321-8.

44. Pattingre S, Tassa A, Qu X, Garuti R, Liang XH, Mizushima N, et al. BCl-2 antiapoptotic proteins inhibit Beclin 1-dependent autophagy. Cell. 2005; 122(6):927-39.

45. Zhu H, Wu H, Liu X, Li B, Chen Y, Ren X, et al. Regulation of autophagy by a beclin 1-targeted microRNA, miR-30a, in cancer cells. Autophagy. 2009;5(6): 816-23.

46. Wang $P$, Liang J, Li Y, Li J, Yang $X$, Zhang $X$, et al. Down-regulation of miRNA-30a alleviates cerebral ischemic injury through enhancing beclin 1mediated autophagy. Neurochem Res. 2014;39(7):1279-91.

47. Pan W, Zhong Y, Cheng C, Liu B, Wang L, Li A, et al. MiR-30-regulated autophagy mediates angiotensin II-induced myocardial hypertrophy. PLoS One. 2013;8(1):e53950

48. Cao J, Ou X, Zhu D, Ma G, Cheng A, Wang M, et al. The 2A2 protein of duck hepatitis a virus type 1 induces apoptosis in primary cell culture. Virus Genes. 2016;52(6):1-9.

49. Sheng XD, Zhang WP, Zhang QR, Gu CQ, Hu XY, Cheng GF. Apoptosis induction in duck tissues during duck hepatitis a virus type 1 infection. Poult Sci. 2014:93(3):527-34.

50. Zhao C, Wang M, Cheng A, Yang Q, Wu Y, Zhu D, et al. Programmed cell death: the battlefield between the host and alpha-herpesviruses and potential avenue for cancer treatment. Oncotarget. 2018;9(55):30704-19.
51. You Y, Cheng AC, Wang MS, Jia RY, Sun KF, Yang Q, et al. The suppression of apoptosis by a-herpesvirus. Cell Death Dis. 2017;8(4):e2749.

52. Guo Y, Shen C, Cheng A, Wang M, Na Z, Chen S, et al. Anatid herpesvirus 1 $\mathrm{CH}$ virulent strain induces syncytium and apoptosis in duck embryo fibroblast cultures. Vet Microbiol. 2009;138(3):258-65.

53. Zhao C, Wang M, Cheng A, Yang Q, Wu Y, Jia R, et al. Duck plaque virus promotes DEF cell apoptosis by activating Caspases, increasing intracellular ROS levels and inducing cell cycle S-phase arrest. Viruses. 2019;11(2):196.

\section{Publisher's Note}

Springer Nature remains neutral with regard to jurisdictional claims in published maps and institutional affiliations.
Ready to submit your research? Choose BMC and benefit from:

- fast, convenient online submission

- thorough peer review by experienced researchers in your field

- rapid publication on acceptance

- support for research data, including large and complex data types

- gold Open Access which fosters wider collaboration and increased citations

- maximum visibility for your research: over $100 \mathrm{M}$ website views per year

At $\mathrm{BMC}$, research is always in progress.

Learn more biomedcentral.com/submissions 